\title{
INFLUÊNCIA DA LUMINOSIDADE NO CRESCIMENTO E FENOLOGIA DE PLANTAS DE PHYSALIS IXOCARPA 'ROXA'.
}

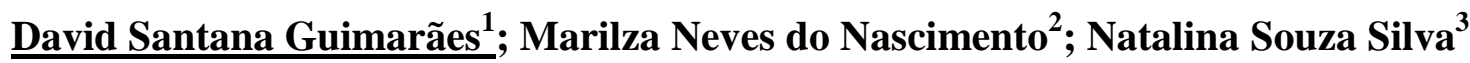 \\ 1. Bolsista,PIBIC/FAPESB, Graduando em Engenharia Agronômica, Universidade Estadual de Feira de Santana, \\ e-mail: davidsg2005@ hotmail.com \\ 2. Orientador, Departamento de Ciências Biológicas, Universidade Estadual de Feira de Santana, \\ e-mail: marilzaagro@ hotmail.com \\ 3. Participante do projeto, Departamento de Ciências Biológicas, Universidade Estadual de Feira de Santana, \\ e-mail: natalina.uefs@yahoo.com.br
}

PALAVRAS-CHAVE: luminosidade; pequenas frutas; cultivo.

\section{INTRODUÇÃO}

Physalis ixocarpa apresenta grande potencial econômico, sendo produzida e comercializada em países da América do Sul e no México, onde é utilizada na preparação de pratos, enriquecendo a culinária dessas regiões. No Brasil, existem poucos estudos sobre as condições ambientais adequadas para o seu cultivo, principalmente na região Nordeste. Essa espécie pode ser uma alternativa de plantio e fonte de renda para pequenos produtores. Entretanto, há necessidade de serem realizados estudos sobre a forma de cultivo e fenologia da planta, para potencializar sua produção. O conhecimento fenológico de uma determinada espécie não permite apenas explicar muitas das reações das plantas às condições climáticas e edáficas, mas também determinar a melhor época de utilização, auxiliando no planejamento para a realização de práticas culturais, como aplicação de fertilizantes, controle de pragas, doenças e plantas invasoras bem como em pesquisas de estimativas de safra, previsão da época de maturação e programas de melhoramento (MORAIS et al., 2008).

Entre os diversos componentes do ambiente, a luz é primordial para o crescimento das plantas, não só por proporcionar energia para a fotossíntese, mas também, por fornecer sinais que regulam seu desenvolvimento através de receptores de luz sensíveis a diferentes intensidades (CARVALHO, 2004). Uma das formas de analisar a influência das diferentes condições de luminosidade nos processos fisiológicos das plantas é através da análise de crescimento e do estudo fenológico. Assim, faz-se importante um estudo da capacidade dessas plantas sobreviverem às condições climáticas do Semiárido brasileiro, região na qual o grupo de pesquisa com Physalis vem aprofundando seus estudos e aprimorando o cultivo. Assim, o objetivo deste trabalho é avaliar o crescimento e caracterizar as fenofases de plantas de Physalis ixocarpa 'roxa' cultivadas em diferentes condições de luminosidade.

\section{METODOLOGIA}

O experimento foi conduzido na Unidade Experimental Horto Florestal - UNEHF- da Universidade Estadual de Feira de Santana (12²14'21"537S; 38 $58^{\prime} 46^{\prime \prime} \mathrm{W}$; altitude de 258 metros), localizada no município de Feira de Santana, Bahia. As sementes foram colocadas para germinar em copos descartáveis de $300 \mathrm{ml}$, contendo uma mistura de terra vegetal (biomix) e areia (2:1), e mantidas em casa de vegetação. Posteriormente, as mudas foram transplantadas para vasos com capacidade de 8 litros contendo o mesmo substrato de cultivo e distribuídos nos diferentes tratamentos pleno sol (100\% de intensidade luminosa) e $50 \%$ de restrição de luz (viveiro tipo telado).

As avaliações fenológicas, onde a partir do $26 .^{\circ}$ dia após a semeadura, onde a cada 14 dias foi realizada a quantificação do número de folhas; número de botões florais, número de flores e número de frutos por planta em todas as amostras da população. As avaliações foram realizadas até a senescência das plantas, durando 124 dias. A avaliação de crescimento das plantas iniciou 40 dias após a semeadura sendo realizada em intervalos de 14 dias até o final do ciclo. Foram utilizadas cinco plantas de cada tratamento para as análises de crescimento. 
As amostras foram sorteadas para garantir a aleatoriedade nas avaliações. Foram feitas medidas lineares: altura da planta $(\mathrm{cm})$; diâmetro do colo. A área foliar foi determinada com o medidor de área modelo $\mathrm{L} 3100 \mathrm{C}\left(\mathrm{mm}^{2}\right.$.

Para obtenção de massa seca, as plantas foram separadas em três partes: folhas, caule e sistema radicular. Após essa separação, esse material foi colocado em sacos de papel identificados e mantidos em estufa de ventilação de ar forçada, a temperatura de $60{ }^{\circ} \mathrm{C}$ até atingir a massa constante, sendo em seguida pesados em balança analítica. A partir dos dados de massa seca e de área foliar, foram obtidos os índices referentes à razão de área foliar (RAF), área foliar específica (AFE) e razão massa foliar (RMF) de acordo com Cairo et al. (2008). O delineamento experimental utilizado foi inteiramente casualizado. A unidade experimental foi composta de quatro repetições de 10 plantas para cada tratamento. Os dados foram submetidos à análise de variância e quando o teste $\mathrm{F}$ foi significativo às médias foram comparadas pelo Teste de T-Student sendo as comparações realizadas em cada coleta.

\section{RESULTADOS E DISCUSSÃO}

Os eventos fenológicos nas diferentes condições de luminosidade encontram-se na tabela 1 .

TABELA 1. Dias transcorridos após a semeadura para 50\% da população expressar os principais estádios fenológicos de Physalis ixocarpa 'roxa' em função de duas condições de luminosidade

\begin{tabular}{llc}
\hline Estádios & Pleno sol & $50 \%$ de luminosidade \\
\hline Início de ramificação & 39 DAS & 53 DAS \\
Botões florais & 39 DAS & 53 DAS \\
Flores abertas & 53 DAS & 53 DAS \\
Frutificação & 109 DAS & 81 DAS \\
\hline
\end{tabular}

Os dados fenológicos mostraram que a quantidade de luz disponível influencia no tempo necessário para ocorrência das fenofases. Desta forma, na condição de pleno sol houve antecipação nos estádios de ramificação, aparecimento dos botões florais e na condição de $50 \%$ de luminosidade a frutificação foi antecipada em 28 dias, sugerindo que em pleno sol as plantas tiveram que sanar outras demandas fisiológicas por estarem mais susceptíveis ao processo da fotorrespiração, sendo mais intenso nessa condição, podendo haver menor disponibilidade de fotoassimilados nessa condição de cultivo para a produção de frutos.

A partir dos dados apresentados na figura 1 verificou-se uma tendência de crescimento em altura muito semelhante nas duas condições de luminosidade. Esses resultados sugerem que nas condições estudadas, a luz não influencia significativamente no crescimento em altura de $P$. ixocarpa. Provavelmente, trata-se de uma característica genética da espécie estudada.

O desenvolvimento do caule do diâmetro de $P$. ixocarpa mostrou-se influenciado pela quantidade de luz disponível no ambiente (Figura 1). Observou-se maior incremento do diâmetro do caule nas plantas cultivadas a pleno sol a partir de 82 dias após a semeadura. Considerando que o desenvolvimento do caule está diretamente relacionado com a atividade cambial, este resultado sugere que as plantas cultivadas a pleno sol têm maior demanda por translocação de seiva entre o sistema radicular e a parte aérea. 

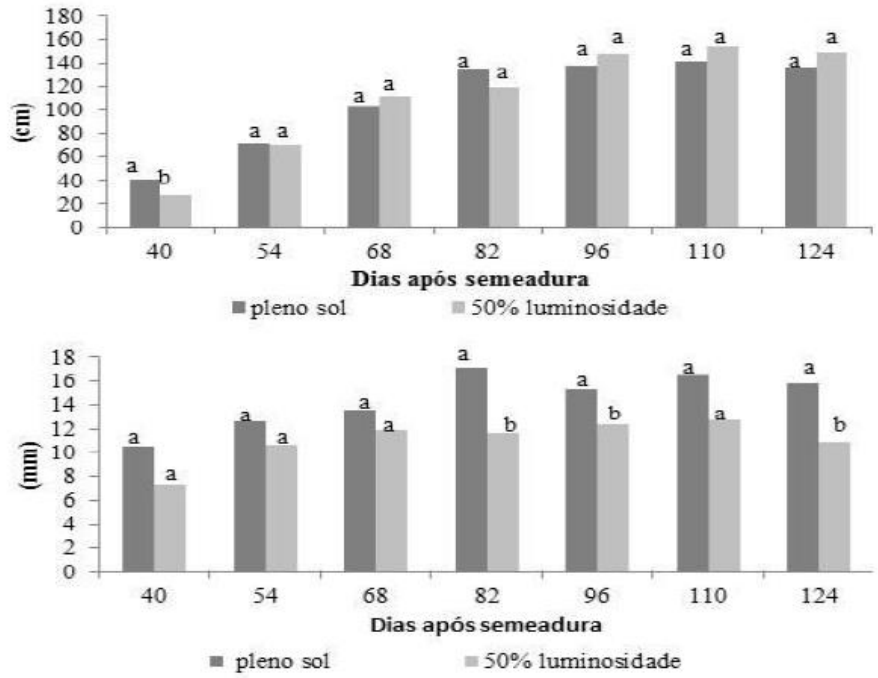

Figura 1: Altura(A) e Diâmetro do caule(B) de P. ixocarpa submetida a duas condições de luminosidade. Universidade Estadual de Feira de Santana-BA, (2016). Médias seguidas pela mesma letra não diferem entre si estatisticamente pelo teste T-Studant a 5\% de significância.

De acordo com dados apresentados na Figura 2 observou-se que as plantas cultivadas a pleno sol apresentaram maior o número de folhas, e reduziram a área foliar, sugerindo tratar-se de mecanismo de proteção ao excesso de radiação e transpiração. Enquanto que as plantas cultivadas em ambiente sombreado reduziram o número de folhas e aumentaram a área foliar para ampliar a interceptação de energia luminosa. Verificou-se maior produção de biomassa nas plantas de $P$. ixocarpa cultivadas a pleno sol e alocação superior para o sistema radicular nessa condição.

Foi observada uma maior alocação de biomassa no sistema radicular em $P$. ixocarpa cultivadas a pleno sol durante todo o ciclo de crescimento, o que está de acordo com resultados encontrados por Lacerda (2010) que encontrou grande diferença na massa seca da raiz entre as plantas cultivadas em ambiente protegido e no ambiente externo, sendo superior neste último.

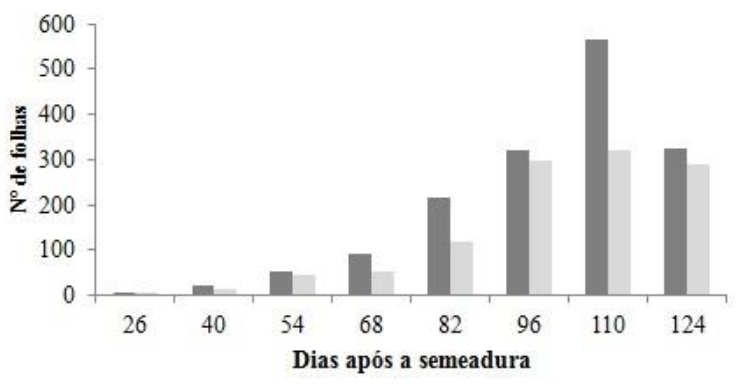

wnúmero de folhas pleno sol número de folhas $50 \%$ luminosidade

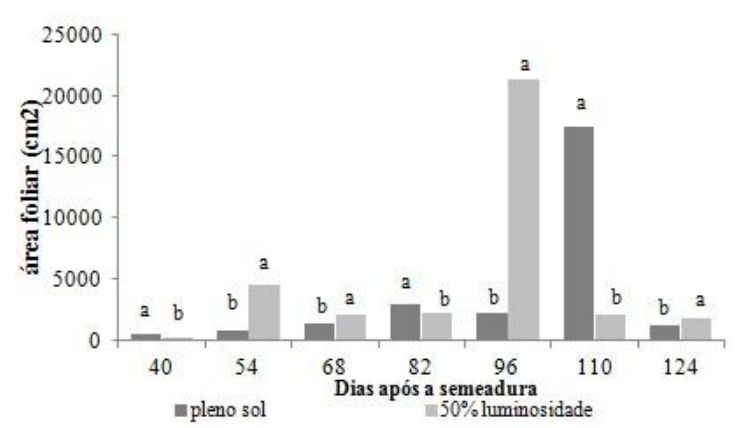

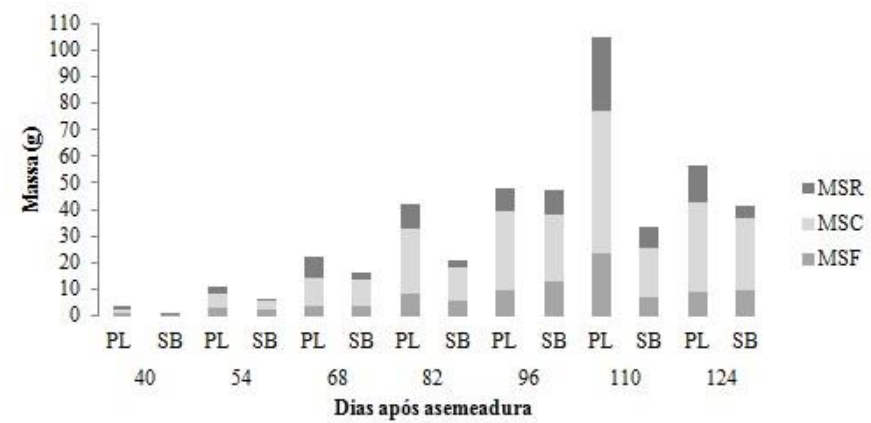

Figura 2: Produção de folhas, média da área foliar de folhas e distribuição de biomassa das folhas, caule e raiz de $P$. ixocarpa 'roxa' sob duas condições de luminosidade durante o ciclo de desenvolvimento. Médias seguidas pela mesma letra não diferem entre si estatisticamente pelo teste T-Studant a 5\% de significância. 
Os maiores valores da AFE das folhas cultivadas em ambiente sombreado foi decorrente da menor espessura do limbo refletindo em um menor peso foliar e do aumento da área foliar, representado na Tabela 2, estratégia adotada para aumentar a interceptação luminosa. Trata-se de uma resposta típica à baixa luminosidade, constituindo uma adaptação morfológica da planta na tentativa de aumentar a área de captação dos raios solares, quando sob restrição de luz (Lacerda, 2010). A área foliar necessária para produzir a mesma quantidade de massa seca nas folhas cultivadas a pleno sol é menor que aquelas cultivadas em ambiente sombreado. Os resultados encontrados estão de acordo com Lacerda et al. (2010) que plantas cultivadas em ambientes sombreados apresentam maiores valores da RAF. A RPF das plantas cultivadas a pleno sol mostraram-se inferior em relação às cultivadas em ambiente sombreado em praticamente todas as avaliações e que as plantas cultivadas em ambiente sombreado reduziram a RPF ao longo do ciclo, seguindo um padrão decrescente.

TABELA 2. Média das variáveis: Área foliar específica (AFE), Razão área foliar (RAF) e Razão da massa foliar (RMF) P. ixocarpa em duas condições de luminosidade

\begin{tabular}{|c|c|c|c|c|c|c|c|}
\hline \multirow[b]{2}{*}{ Condição de luminosidade } & \multicolumn{5}{|c|}{ Data após semeadura } & \multirow[b]{2}{*}{110} & \multirow[b]{2}{*}{124} \\
\hline & 40 & 54 & 68 & 82 & 96 & & \\
\hline \multicolumn{8}{|c|}{ Área foliar específica $\left(\mathbf{d m}^{2} \cdot \mathrm{g}^{-1}\right)$} \\
\hline Pleno sol & $51.72 \mathrm{~b}$ & $30.43 \mathrm{~b}$ & $35.55 \mathrm{~b}$ & $33.85 \mathrm{a}$ & $22.37 \mathrm{~b}$ & $17.47 \mathrm{a}$ & $13.49 \mathrm{a}$ \\
\hline $50 \%$ luminosidade & $97.10 \mathrm{a}$ & $45.32 \mathrm{a}$ & $51.67 \mathrm{a}$ & $41.17 \mathrm{a}$ & $35.31 \mathrm{a}$ & $30.17 \mathrm{a}$ & $19.17 \mathrm{a}$ \\
\hline \multicolumn{8}{|c|}{ Razão da área foliar $\left(\mathrm{dm}^{2} \cdot \mathrm{g}^{-1}\right)$} \\
\hline Pleno sol & $22.05 \mathrm{a}$ & $9.27 \mathrm{~b}$ & $6.28 \mathrm{a}$ & $6.74 \mathrm{a}$ & $4.29 \mathrm{~b}$ & $3.60 \mathrm{a}$ & $1.94 \mathrm{~b}$ \\
\hline $50 \%$ luminosidade & 39.39 a & $18.25 \mathrm{a}$ & $16.26 \mathrm{~b}$ & $11.33 \mathrm{a}$ & $9.59 \mathrm{a}$ & $6.77 \mathrm{a}$ & $4.40 \mathrm{a}$ \\
\hline \multicolumn{8}{|c|}{ Razão da massa foliar } \\
\hline Pleno sol & $0.44 \mathrm{a}$ & $0.29 \mathrm{a}$ & $0.18 \mathrm{~b}$ & $0.19 b$ & $0.20 \mathrm{a}$ & $0.21 \mathrm{a}$ & $0.16 \mathrm{~b}$ \\
\hline $50 \%$ luminosidade & $0.43 \mathrm{a}$ & $0.39 \mathrm{a}$ & $0.30 \mathrm{a}$ & $0.28 \mathrm{a}$ & $0.27 \mathrm{a}$ & $0.22 \mathrm{a}$ & $0.24 \mathrm{a}$ \\
\hline
\end{tabular}

\section{CONCLUSÃO}

A quantidade de luz disponível no ambiente influencia no crescimento e no estabelecimento das fenofases de P. ixocarpa.

\section{REFERÊNCIAS}

CAIRO, P. A.R.; OLIVEIRA, L. E. M. de. MESQUITA, A.C.; Análise de Crescimento de Plantas. Vitória da Conquista: Edições UESB, 2008.

CARVALHO, N. O. S. Germinação e Crescimento Inicial de Licuri(Syagrus coronata (Mart.) Becc.) submetidas a diferentes níveis de luminosidade. 2004. 51 p. Dissertação (Mestrado em Botânica). Universidade Estadual de Feira de Santana. LACERDA, C. F.; VIEIRA, M. R.; CARVALHO, C. M. de.; NOBRE, J. G. A.; NEVES, A. L. R.; RODRIGUES, C. F. Análise de crescimento de milho e feijão sob diferentes condições de sombreamento. Revista Brasileira de Ciências Agrárias, v.5, n.1, p.18-24, 2010. MORAIS, H.; CARAMORI, P. H.; KOGUISHI, M. S.; RIBEIRO, A. M. DE A. SCALA Fenológica detalhada da fase reprodutiva de Coffea arabica. Bragantia, Campinas, v.67, n.1, p.257-260, 2008. 